\section{ENTOMOLOGICAL NOTES.}

Dr. William Patten has been appointed professor of biology at the University of North Dakota at Grand Forks.

Dr. Clarence M. Weed, of the Ohio experiment station, has editorial charge of the department of entomology of the American naturalist.

Mr. Jerome McNeill of Moline, Ill., has been chosen professor of biology and geology at the State University of Arkansas at Fayetteville.

Cordulina. - In a note to Dr. H. A. Hagen the Abbé Provancher writes that he has not visited Mt. Yamaska since $\mathrm{r} 877$. So far as known his original specimens of Epitheca yasmaskanensis are the only ones extant. Mr. Lintner also writes that he has not taken Cordalia lintneri since his first catch.

Kolbe's Guide.-Part 4 of Kolbe's German Guide to the knowledge of Insects, p. I77-224, is entirely devoted to the antenuae and mouth-parts with a large number of simple but instructive and mostly original figures. This excellent work was originally announced to be completed in six or eight parts, but as the author has not yet covered more than one-sixth of the ground he laid out in his prospectus, it is more likely to continue to twenty.

Greenland Insects. - Aurivillius has begun in the Handlingar of the Swedish. Academy a study of the insect fauna of Greenland, which he is undertaking with his usual thoroughness, as the first instalment, including the lepidoptera and hymenoptera, shows. It is accompanied by three plates, and several excellent figures in the text. $\mathrm{He}$ records 28 species of lepidoptera and 17 of hymenoptera. The most numerous genera of lepidoptera are Agrotis, 5 species, Plusia and Hadena, 4 species each. The only new species are one each of Anarta, Pimpla and Banchus.
EARLy LAST AUgust a green cockroach of considerable size, Panchlora nivea (Linn.), was found alive, with a multitude of young ones just hatched, in the bath room of a house on Lafayette St., Salem, Mass., and sent to Mr. S. H. Scudder for determination by Prof. E. S. Morse. It is a native of Cuba aud Central America. It is curious that Mr. Scudder has also in his collection a specimen marked as found flying in a store in Boston, 26 December, 1878 , on the authority of the late Dr. Samuel Kneeland.

The Apple Maggot, Trypeta pomonella, is the subject of an elaborate report by Prof. F. L. Harvey of the Maine State College. The investigations were made in $\mathrm{r} \$ 88$ and I 889 chiefly at Orono, though the date and place of publication are not noted. The species is described and figured in all its stages and its life-history and habits are given in detail. As the larvae do not leave the fruit until it falls from the trees the thorough and universal destruction of windfalls is recommended as the best remedy.

Lepidoptera IndicA. - Three parts of Moore's Lepidoptera Indica, including 80 pp. of letter press and 24 plates, have now appeared and the author has not yet more than half completed the euploeinae with which he begins his work and of which thirteen genera and thirty-five species are so far characterized; this gives a lively impression of the difference between that fauna and our own. The additions to our knowledge of the earlier stages are interesting; the caterpillars and chrysalids of seven species are given (from one to three figures of each) of as many genera, and their peculiarities certainly seem to support the closer subdivision of these Eastern euploeinae of which Mr. Moore has been the foremost supporter. About half of these same species have before had their earlier stages figured, but of these as well the illustrations are new; never before have the euploeinae been so well illustrated in their earlier life. All the figures appear to have been put upon the stone by Mr. Moore's son. 
What is THE CAUSE of the gradual extermination of insects in certain places? Is it the changes incident to growth of population? It is well known that Chrysophanus dispar formerly found in England is now no longer known there; as the French might say, dispar has disparu. Mr. Jenner Wier writes that Aporia crataegi was a common species in several parts of Sussex, notably at his father's, about 8 miles from Lewes, where it was to be seen in numbers every year, but now for forty years he has seen but one specimen; nor do his Sussex friends take it. He states that it has also disappeared from the New Forest where he used to take it up to ten years ago, and from Monmouthshire, where it was once common.

The Tenth Part of the current series of Edwards's Butterflies of North America deals with two species from the eastern half of the continent, two from the western, both of the latter species of Argynnis, of which little more than the bare description is given in the text. Of each of the eastern species, however, Argynnis alcestis and Satyrodes canthus, a full life-history is given with abundant illustration, and, of course, of the highest excellence as Mr. Edwards deals with no other. The statements regarding the difference of behavior and coloration of different caterpillars of the same species is full of interest and shows the necessity for repeated observations. The exceptional autumn activity recorded of the young caterpillar of $A$. alcestis may possibly have been due to an unwonted climate, as they were transferred while in the egg-state from Chicago to Coalburgh. While one does not like to find fault with a work of such marked excellence, it is a pity that the author cannot find a better way of describing the position of the tubercles of the caterpillar than that employed, which often reads like a multiplication table, locates them vaguely at best, and omits much that is distinctive.

Long-Lived Zopherus.--Mr. S. H. Scudder has in his possession four specimens of Zopherus bremii, one of the tenebrionidae from Yucatan, which is used as an ornament to the dress in Central America by being belted and chained with gold; the natives call them Makatch and they are popularly supposed to live on air. They were received from Stephen Salisbury Esq. of Worcester who has had them alive for five years. They have been kept in a wire cage in which is a large piece of half decayed wood, which they evidently gnawed more or less, making some chips, but whether or not they devoured it was a matter of doubt until some birch fungi were introduced; these seemed to meet with more favor and especially one which had a partially black interior; it was soon seen that some of the chips were of a darker color, and examination showed in all, both gray and black, a remarkable uniformity in size; closer scrutiny showed them to be unquestionably faeces, all being of the same form and made up of a pressed agglomeration of vermiform series of particles. The amount however is ridiculously small, for a dozen of these beetles together would not furnish a thimble full in a year.

Notice of Meeting, Association of Official Economic Entomologists.

The second annual meeting of the Association of Official Economic Entomologists will be held at the university buildings, Champaign, Ill., November IIth to I5th proximo, at the same time and place as the meeting of the Association of Agricultural Colleges and Experiment Stations. The committee on Entomology of the latter association will meet at the same time.

Members expecting to attend, will confer a favor upon the officers if they will announce the fact, and will send titles of papers to be read or topics they desire discussed to the Secretary.

All are earnestly requested to be present if possible.

John B. Smith, Secretary, New Brunswick, N. J.

No. 169 was issued 10 May, I89o.

" I 70 was issued II July, I890.

“ I7I was issued I9 August I890. 

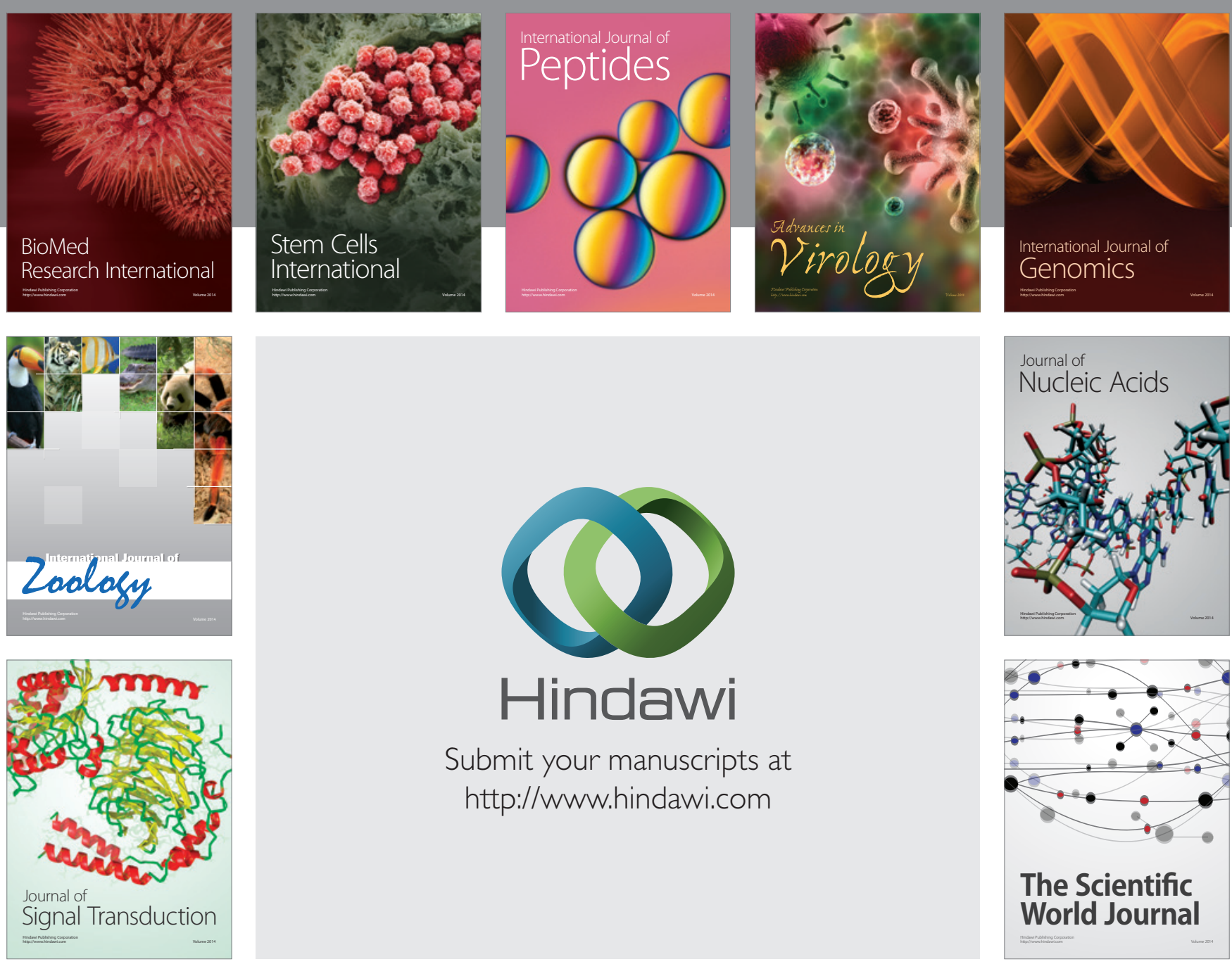

Submit your manuscripts at

http://www.hindawi.com
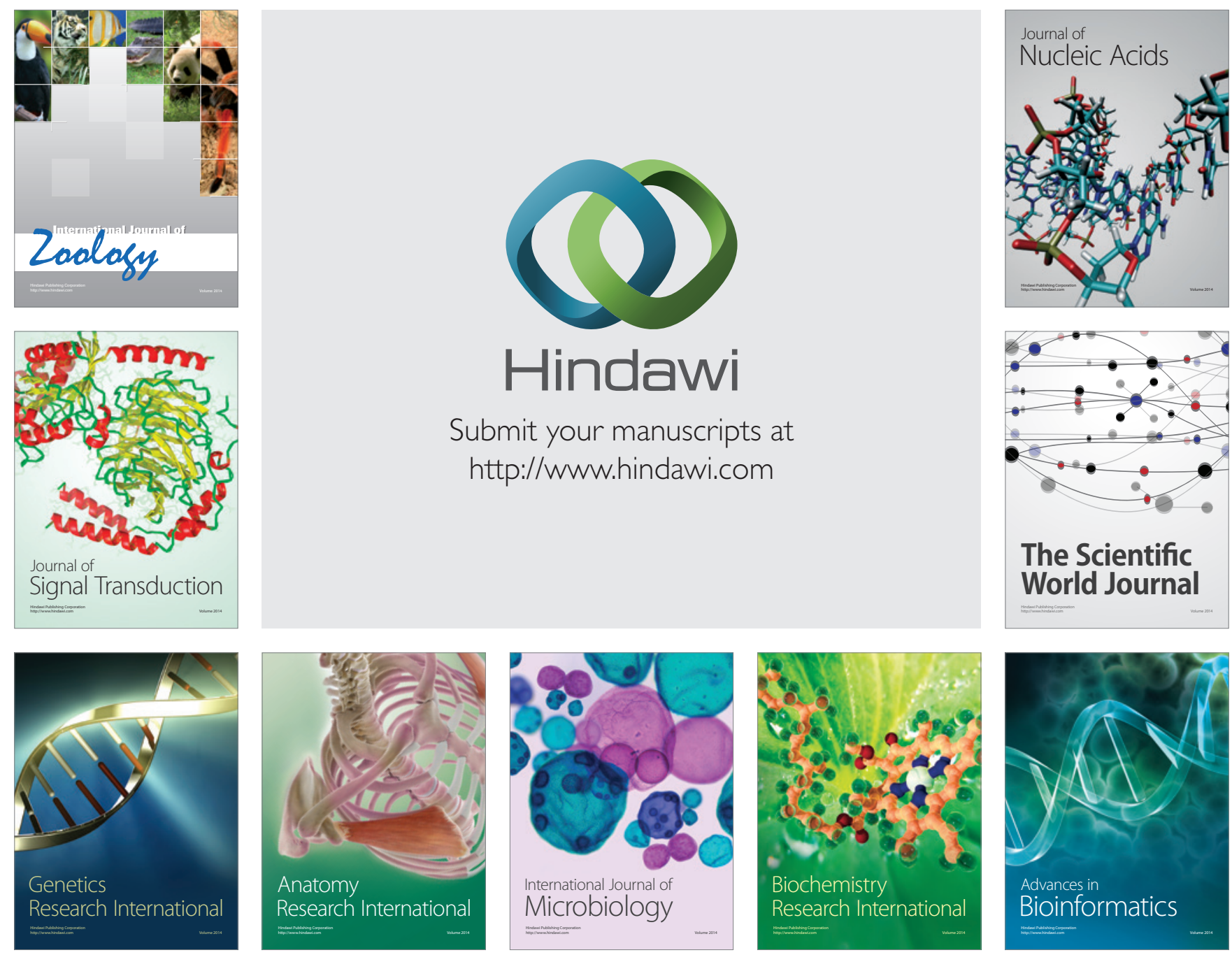

The Scientific World Journal
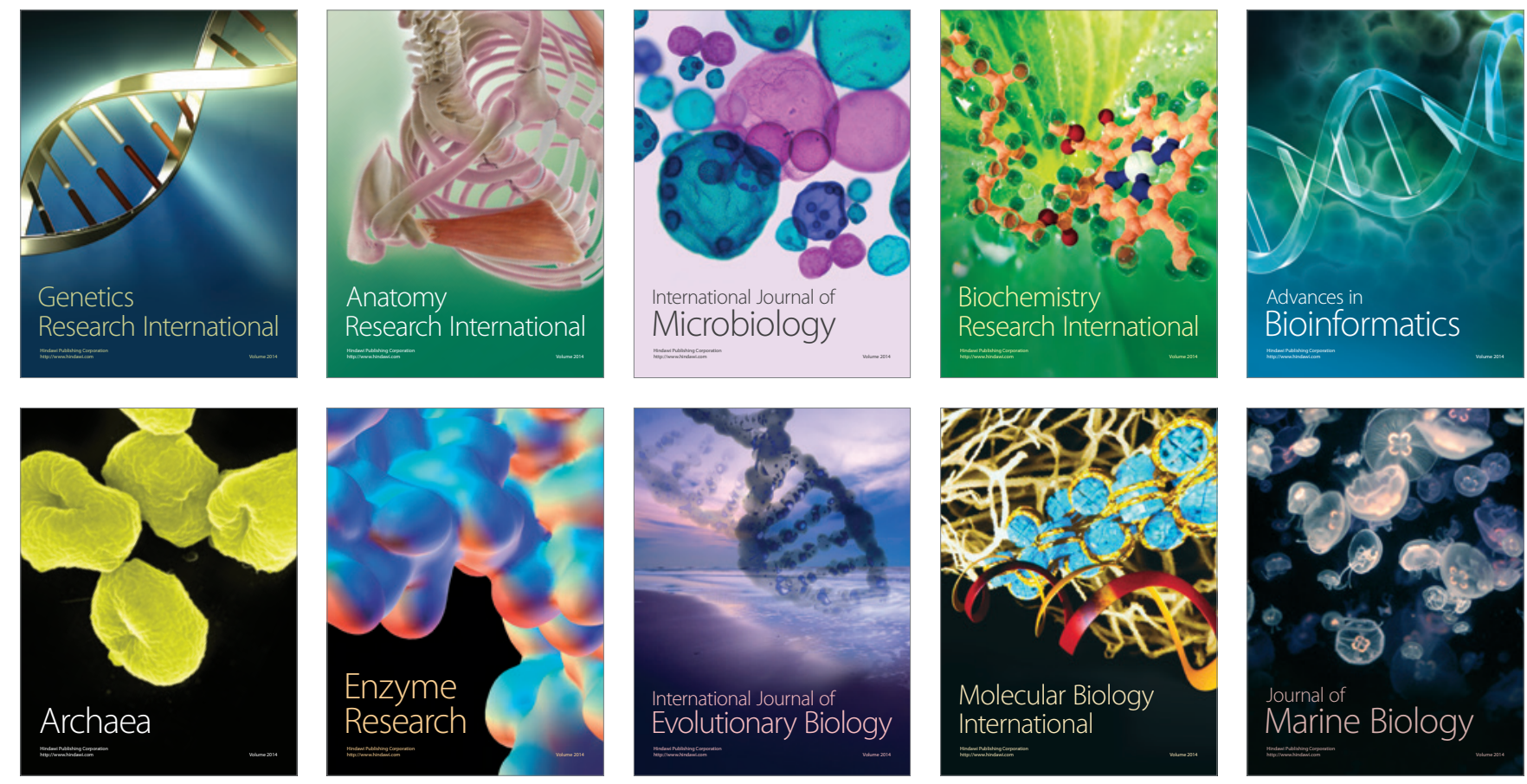